\title{
The Challenges of Studying in Australia for Saudis Male International Students
}

\author{
Naif Daifullah Alsulami \\ Umm Al-Qura University \\ Mecca \\ Saudi Arabia
}

\begin{abstract}
This article reports on the analysis of a narrative discussion group facilitated by the author as a part of a larger study. The participants of this study are six male Saudi Arabian international students who are enrolled at different universities in Victoria in Australia. This article aims to answer this question: what are some challenges that male Saudis experience as international students in Australia? Participants announced some challenges that they have experienced as international students in Australia. These challenges include academic challenges, cultural challenges, personal challenges and challenges with the Saudi Cultural Mission (SACM). Recommendations for future researchers and implications for practitioners are provided.
\end{abstract}

Keywords: Saudi international students, Challenges of international students, Australia

\section{Introduction}

The most recent statistics, issued in 2016, indicate that 174,333 Saudis, including both undergraduate and postgraduate students, are currently being sponsored as they study abroad (Ministry of Education 2016). The rapid rise in the number of Saudi international students is likely due to the appeal of the program, which reflects the keenness of the Saudi government to develop the country by sending students to study abroad and then return home with high quality knowledge and skills (Ministry Education 2016). In 2015, more than 7339 students, 77.5 per cent male and 22.5 per cent female, were reported to have enrolled in Australian universities, undertaking higher education courses (SACM 2015).

Despite the benefits of studying in Australia, male Saudi Arabian international students immediately meet a country that is completely different from their home country in terms of culture, language, lifestyle and educational systems. In addition to the culture shock they might experience, these male students also have language barriers due to the prominent use of Arabic as their first language. This research aims to explore some challenges encountered by male Saudi Arabian international students studying in Australia. The main research question of this research is: what are some challenges experienced by male Saudis as international students in Australia?

Previous studies have discussed the experience of Saudi international students such as (Binsahl and Chang 2012; Binsahl, Chang and Bosua 2015). However, these studies focused on the female Saudi international students. As a male Saudi international student studying in Australia since 2012, the researcher holds adequate knowledge and experience the experiences of male Saudis differ than those of their female counterparts. This research, therefore, is filling the gap in the literature by adding the focus of study on the male Saudis students. Although there were some studies discussing male Saudis experience in Australia such as (Midgely 2009a; 2009b), the number of research subjects was very small (e.g. two male Saudis studying the same major that is Nursing). The present study attempts to contribute to the body of knowledge by working on a larger number of subjects (six male Saudi international students) studying in different fields, such as: business, information technology, emergency care and nursing and educational technology. It also includes various universities in Victoria and different regions in Saudi Arabia (See section 4). This various contexts and uniqueness enhance the research findings and differentiate this study from the previous ones, while at the same time enrich the literature.

The structure of this article begins with the contextualisation of the study, followed by the literature review. Consecutively, the article presents the research methodology, findings, and discussions. Finally, this research concludes with some implications and recommendations based on the results. 


\section{Contextualising the study}

This study focuses on the Saudis students' studying experience in Australia whose home culture differs immensely from the host culture. As a country with majority Muslims, Saudi Arabia's culture may 'clash' to host culture in which Islam is a minority religion. Therefore, some clarification on the concept of culture is essential.

Culture can be defined in many ways. Johnson and Christensen (2004) conceptualised it as 'the shared attitudes, values, norms and practices, patterns of interaction, perspectives, and language of a group of people' (pp. 147). Moreover, Said (1993) defined culture as 'all those practices, like the arts of description, communication, and representation, that have relative autonomy from the economic, social, and political realms and that often exist in aesthetic forms, one of whose principal aims is pleasure' (pp. xii). Stuart Hall, a well-known and influential figure in social theory, argued 'culture is about shared meanings' (Hall 1997a:1). Therefore, people who belong to the same culture 'interpret the world in roughly the same ways and can express themselves, their thoughts and feelings about the world, in ways which will be understood by each other' (Hall 1997a:2).

In the context of Saudi Arabia, since the establishment of the country 1932 (Long and Maisel 2010), there has been a collision between tradition and modernisation efforts in the country. The leaders of the kingdom have attempted to maintain a balance between cultural norms, Islamic values and modernisation (Ayub, Kassim and Zain 2014). In their book, The Kingdom of Saudi Arabia, Long and Maisel (2010) they describe Saudi Arabia as 'a country of startling contrasts - a huge landmass and a small population; a barren desert terrain situated over great oil wealth; a traditional Islamic society undergoing rapid modernization; a closed society that is often in the news' (pp. 1).

Islam is the official religion and it is practiced by $100 \%$ of Saudi Arabians (Al-Nusair2000). Arabic is the official language of Saudi Arabia. All Saudi citizens are required to practise the teachings of Islam (Lippman2004). The king is also known by his religious title, the 'Custodian of the Two Holy Mosques'. These mosques are Almasjid Alharam (The Holy Mosque) in Mecca, and the Prophet's Mosque, in Madinah. The symbol of Islam is written on the flag of the country (the slogan 'There is no God but Allah the Almighty - and Muhammad is the Messenger of Allah').

As the Saudi religious scholars have a power in the country and in most decisions, 'the king listen to the opinions of Saudi religious scholars in a committee known as the council of Senior scholars' (Alsulami 2016: 6). With the agreement of politicians, those religious scholars have formulated some dimensions of Saudi culture that differentiate the country from the others in the world. Saudi Arabia does not permit its citizens to practice other faiths. Selling alcohol is not tolerated; cinemas are not found in the country; and when it is prayer time in the mosques, all shops must be closed until the prayers are over (Hilal2013). Moreover, there are strong gender segregations in the country, either in education or public life, including in restaurants. Alsulami (2016) has justified how and why some cultural dimensions in Saudi Arabia, such as gender segregation, have been theorised and practised. Hence, it is very likely that Saudi international students will experience many challenges upon their arrival to Western countries, including Australia due to the great differences between the cultures.

\section{Literature Review}

\subsection{Challenges of international students}

Previous studies indicated that international students experience many challenges while studying abroad. The challenges of international students can be classified under three categories: academic, cultural and personal (see Sections 3.1.1; 3.1.2; 3.1.3).

\subsubsection{Academic challenges}

Academic challenges have been experienced by international students especially when they travel to study in a country that has a different language and educational system. International students experience troubles in classes, particularly at the beginning, due to the language barrier. It is not easy for international students to fully understand what the lecturers want or say, which affects class participation. Conversely, lecturers cannot fully understand the needs of international students if they cannot express themselves correctly. Although international students usually are successful students in their home country and are considered academic stars, they may experience intellectual and emotional difficulties because they fail to understand lectures and achieve the grades they are used to achieve when they were in their home country. 


\subsubsection{English as one of the obstacles}

Many researchers have found that the English language is one of the obstacles facing international students (AlShehri 1989; Guantlett 2006; Hofer 2009; Jammaz 1972; Novera 2004; Sawir 2005; Shabeeb 1996; Sharma 1971). No doubt, there is a relationship between the language barrier and challenges regarding academic development, including the completion of assignments, class discussion, interactions with university employees in English, taking notes and understanding lecturers (Abualkhair 2013; Sharma 1971). From the beginning of the seventies in the last century, researchers found that using academic English is one of the difficulties that face international students. Sharma (1971) focused his study on the adjustment problems experienced by nonEuropean graduate students enrolled at selected universities in the state of North Carolina, United States. The respondents, 195 students, said they struggled with using academic English as well as problems in class like taking notes, understanding lectures, participation and discussions. In a study similar to this one that is considered the earliest investigation of Saudi international students, Jammaz (1972) conducted a quantitative study of the issues and problems of Saudi students studying in the United States; he particularly focused on adjustment problems. He received 345 replies out of 400 questionnaires sent to Saudi students studying in the United States. He found that English is considered the greatest obstacle faced by students, especially with taking notes, discussions in class and reading.

A later study corroborated Jammaz's. According to Shabeeb (1996), the English language constitutes the biggest adjustment problem for international students. Shabeeb conducted this quantitative study by using the Michigan International Students Problem Inventory (MISPI) to study problems regarding the adjustments of Saudi undergraduate and graduate students at six colleges and universities in Washington. He found that studying and using English is the biggest adjustment problem for students. Moreover, it is one of the concerns of Saudi international students while they study abroad. In the spring term of 1989, Al-Shehri surveyed Saudi graduate students in the United States by using the MISPI to find the concerns of Saudi students. The sample size of this study was 780 males and 70 females from a total of 1,210 Saudi students studying in the US at that time, and 345 students returned the survey instrument. The researcher found one of the areas considered the greatest concern to Saudi students is using English in, for example, writing essays and academic records such as grades.

\subsubsection{Challenges as the result of a lack of language proficiency}

Because of a weakness in foreign students' language proficiency, some related problems may occur such as doing assignments, class discussions as well as difficulties in contacting faculty and staff, for instance. Abualkhair (2013) examined the experiences of eight Arab Muslim international students studying in the United States regarding pedagogy, curriculum and interactions with faculty. The results of this study revealed that Arab Muslim international students experience challenges with their academic development, including the completion of assignments, oral class discussions and interactions with faculty in English. It can be clearly shown that the obstacle of the English language still exists, and international students must encounter this drawback. The main reason behind this obstacle is a weak command of English before travelling to study abroad (Ankawi 2015; Sawir 2005). In a study conducted to examine the language difficulties of international students from five Asian nations studying in Australia, Sawir (2005) found that the source of their learning difficulties was based on a weakness in students' language usages before coming to Australia. However, current international students experience less adjustment challenges with the English language barrier than students in the last century. For example, Hofer (2009) examined the adjustment issues of Saudi Arabian students studying in the state of Missouri, United States. He conducted mixed methods research (qualitative and quantitative) and sent the MISPI to students; 81 out of 419 respondents returned their questionnaires. Although students reported some minor problems such as living and dining, the English language and financial aid, Hofer stated that, compared with previous Saudi students, current students indicated fewer problems with adjustment challenges, including the English language.

\subsubsection{Changing the majors of international students}

One of the academic challenges of international students is changing their majors after enrolling in a university. Al-Harthi (1987) investigated this problem, and his study tried to answer the main question regarding why some students change their majors after enrolling in United States universities. He used quantitative methods, and he mailed questionnaires to different samples. He mailed 50 representatives of government-sponsored agencies in Saudi Arabia (43 responded), 30 academic advisors at the Saudi Cultural Mission in the United States (19 responded), and 200 undergraduate students (114 responded). The results showed that there is a big gap between Saudi high schools and higher education in the United States. 
In addition, there was no preparation for students to pursue their higher education in the host country. Furthermore, students reported that their academic desires were not considered when making scholarship decisions. Subsequently, students studied undesirable majors.

\subsubsection{Cultural challenges}

International students not only encounter the challenges associated with being students but also they encounter challenges associated with cultural differences (Binsahl and Chang 2012). Because many international students usually travel to study abroad in a country with many cultural differences including language, religion, communication style, food, educational system and lifestyle, culture shock may be experienced by some international students.

\subsubsection{Culture shock}

Culture shock has been defined by many researchers such as Stewart (2003), who defined culture shock as

'the state of being cut off from cultural cues and known patterns with which you are familiar, and living or working over an extended period of time in a situation that is ambiguous, having your own values which you had heretofore considered absolutes brought into question and being continually put into positions in which you are expected to function with maximum skill and speed but where rules have not been adequately explained' (pp. 105).

\subsubsection{Cultural differences}

Many studies have found that international students who travel to learn in a country with many cultural differences may encounter a hard time in adapting to a new culture. One study conducted by Mukthyala (2013) evaluates the experiences of Indian international students. The sample of this study constituted eight Indian international graduate students at a Midwestern American university. The results indicated that Indian international students typically faced challenges in adjusting to cultural differences. Moreover, Pan and Wong (2010) concluded their study, which compared the negative affect and acculturative stressors between Chinese students in Australia and mainland Chinese students in Hong Kong, by asserting that it is not easy for Chinese international students to adapt to a host country with greater cultural differences.

Furthermore, Gauntlett (2006) investigated the challenges of Gulf-sponsored students studying in Australia and found some challenges that Gulf-sponsored students had, including challenges regarding religious and cultural differences. Gulf students, including Saudi students who travel to learn in Western countries, encounter many problems with cultural differences. To elaborate, one aspect of Saudi culture in education is the segregation between genders in all stages of education, including higher education. Thus, Saudi international students who travel to study in Western countries experience learning with different genders for the first time in their lives. Alhazmi and Nyland (2013) examined one aspect of Saudi culture, which is gender segregation and how this aspect may affect Saudi students' engagement with the Australian community. Two Saudi international students, both male and female, who are studying at Australian universities, were interviewed. The results of this study demonstrated that the Saudi culture of extreme gender segregation has affected Saudi students' experiences especially, in their ability to relate to their peers in a coeducational environment.

Additionally, many married Saudi international students take care of dependent family members in a host country, which sometimes causes some intellectual and emotional problems, as shown in a study conducted by Midgley (2009a), who talked about a unique topic regarding Saudi international students in Australia. He asserted that this topic is not discussed elsewhere: namely, the stress of worrying about dependent family members who are coming with international students to a host country and might face some problems related to loneliness and homesickness. He found that married Saudi students are worrying about their wives, who were struggling to adjust to the Australian culture and, consequently, were feeling isolated or, sometimes, very afraid. One of the participants talked about his concerns for his wife by saying: when we are at Uni, our minds are at home! Although some aspects of Saudi culture seem unfamiliar to many cultures all over the world, Saudi international students value this culture, appreciate it and do not feel comfortable living away from their own culture. According to Al-Jasir (1993), who conducted a quantitative-method study to examine the social, cultural and academic factors associated with the adjustments of Saudi students in the United States, the majority of students reported very little change in their values. Al-Jasir also reported that Saudi students appreciate their own culture and, as the length of their sojourn increases, they become increasingly uncomfortable in the United States. 
In contrast, Saudi international students are sometimes full of contradictions in regards to adapting to and immersing themselves in a new culture. Sometimes, students have the same age, same course, same city and totally different experiences. For instance, in a study of two male Saudi international students of a similar age, studying the same course at the same Australian university, Midgely (2009b) found that these students had very different experiences resulting from their different responses to the challenges of living and studying in Australia. One of them prefers to practise the same Saudi cultural norms and does not prefer trying another culture. Another prefers immersing himself in Australian culture and ignores the practice of Saudi culture.

\subsubsection{Personal challenges}

The issues classified as the personal challenges of international students have been discussed by many researchers such as financial aid (Al-Shehri 1989; Hofer 2009; Shabeeb 1996; Sharma 1971), homesickness (Caldwell 2013; Sharma 1971), isolation and loneliness (Sawir et al. 2008), social support (Khawaja and Dempsey 2008), friendships within the local community (Abdul Latif et al. 2012; Al-Jasir 1993; Mukthyala 2013) and discrimination (Rundles 2012).

\subsubsection{Financial aid}

Unlike some international students who are sponsored by governments, many international students struggle with financial aid. Sharma (1971) focused his study on the adjustment problems experienced by non-European graduate students enrolled at selected universities in North Carolina. The respondents were 195 students who announced financial problems. Moreover, in the spring term of 1989, Al-Shehri surveyed Saudi graduate students in the United States by using the MISPI to find their concerns. The sample size of this study was 780 males and 70 females out of a total of 1,210 Saudi students in the United States at that time, and 345 students returned the survey instrument. The researcher found that the greatest concern to Saudi students is financial aid. Furthermore, unlike the previous studies conducted by using quantitative methods, Hofer (2009) conducted mixed-methods (qualitative and quantitative) research to examine the adjustment issues of Saudi Arabian students learning in the state of Missouri, USA. He sent the MISPI to students; 81 out of 419 questionnaires were returned. Students here named financial aid as one of their problems. However, the financial challenges might not be experienced by King Abdullah Scholarship Program -KASP-'s students compared to the Saudi-sponsored students in the eighteens and nineteens, particularly after the financial increase approved by the council ministers in 2013 (Mbt3th 2013). The current KASP's students really enjoy many financial advantages, including full university tuition coverage, allowance for materials and a monthly stipend for living expenses. They also receive complete medical and dental insurance and annual round-trip airfare vouchers for themselves and their families. The students also receive rewards for high grade point averages.

\subsubsection{Isolation/loneliness}

Due to moving to a new country and new culture, the majority of international students experiences loneliness and isolation problems, especially in the first few months. For instance Sawir et al. (2008) conducted a study about the security of international students. It was found that two-thirds (approximately 133 out of the 200 students interviewed) experienced isolation and/or loneliness problems, particularly in the first few months. Therefore, it is important for international students to form friendships either with local or other international students to avoid loneliness.

\subsubsection{Friendships within the local community}

As the study of Sawir et al. (2008) recommended, the best way to avoid loneliness and isolation problems is to form friendships between international and local students. Although many international students experience difficulties in building relationships with domestic students (Mukthyala 2013) or have a low level of interaction with local students (Al-Jasir1993), some international students have announced that it is easy to form friendships with domestic students (Abdul Latif et al. 2012).

Although some of the previous studies examined the challenges of international students while studying abroad (Khawaja and Dempsey 2008; Mukthyala 2013; Pan and Wong, 2010; Rundles 2012; Sawiret al. 2008), none of these studies examined the challenges of Saudi international students. However, the challenges of Saudi international students have been examined by some researchers (Al-Harthi 1987; Al-Shehri 1989; Hofer 2009; Jammaz 1972; Shabeeb1996), but all the aforementioned studies were conducted in the United States and were conducted by using quantitative methodology, except for Hofer (2009), used mixed-methods research. 
Hence, this research will fill the gap in the literature regarding the experiences of male Saudi international students by conducting this study in Victoria, Australia, and by using qualitative methods to examine this issue indepth and in detail.

\section{Methodology}

The participants of this study are six male Saudi Arabian international students who are enrolled at universities in Victoria. A small number of participants was chosen because, according to Denzin, Miles and Huberman (1994) 'Qualitative researchers usually work with small samples of people, nested in their context and studied in-depth unlike quantitative researchers who aim for larger number of context-stripped cases and seek statistical significance' (pp. 27). The participants are studying different fields, including business, information technology, emergency care and nursing and educational technology. One participant is still in the English language stage. The participants range in age from twenty to 38 years old and have lived in Victoria from one to four years. Five of the participants are married, while one self-identified as single. The participants are only male, not female, due to cultural limitations between Saudi males and females; it was difficult to find Saudi females who will agree to be interviewed by a Saudi male. Participants are from different universities in Victoria, including: Monash, Swinburne, RMIT, Deakin and Monash College. Moreover, the participants are from different regions of Saudi Arabia, including Riyadh, Abha, Jazan, Taif and Medina. It is important to have students from different regions in Saudi Arabia to reflect the cultural diversity in Saudi Arabia. Listening to different perspectives will surely enhance the findings of this study. The researcher used anonymous for the participants' names.

In this study, the data were collected by using a focus group interview with semi-structured questions, as that was the most relevant approach for unveiling the experiences of male Saudi international students at Victorian universities. All participants were invited to participate in a focus group interview at a day and time agreed by them. The discussion took place in a study room in Matheson Library at Monash University-Clayton campus. This focus group interview had this main question:

What are some challenges do you experience as Saudis international students in Australia?

The data analysis was conducted in three phases. In the first, after conducting the focus group interview in the Arabic language, the researcher transcribed it verbatim, word by word, into a document written in Arabic. In the second phase, the researcher translated the Arabic document into English. The third phase incorporated crossanalysis of the data, that is, the interpretation and creation of themes by the researcher. Here, the researcher adopted a thematic content analysis approach. One common method for analysing qualitative data is to reduce the content of a large body of data to a smaller number of central themes or patterns (Patton, 2002).

\section{Findings and Discussions}

\subsection{The challenges for male Saudi international students}

Having reviewed some previous studies in literature review section, it is found that previous studies indicated that international students experience many challenges while studying abroad. The challenges of international students can be classified under three categories: academic, cultural and personal. Academic challenges such as English language obstacle, challenges as the result of a lack of language proficiency and changing the majors of international students (see Sections 3.1.1). Cultural challenges including culture shock and cultural differences (see Sections 3.1.2). Personal challenges such as financial aid, isolation/loneliness and friendships within the local community (see Sections 3.1.3).

This study, however, pull out some different findings from the previous studies. When asked about the challenges they encountered as international students in Australia, the participants of this present study mentioned four main challenges, including: academic challenges (e.g. English language barrier and bad experiences with Englishlanguage teachers), cultural challenges (e.g. adapting to a new lifestyle, dealing with cultural differences and culture shock), personal challenges (e.g. feelings of loneliness and bad experiences with previous Saudi international students) and finally challenges with the Saudi Cultural Mission in Australia (see Chart 1). 


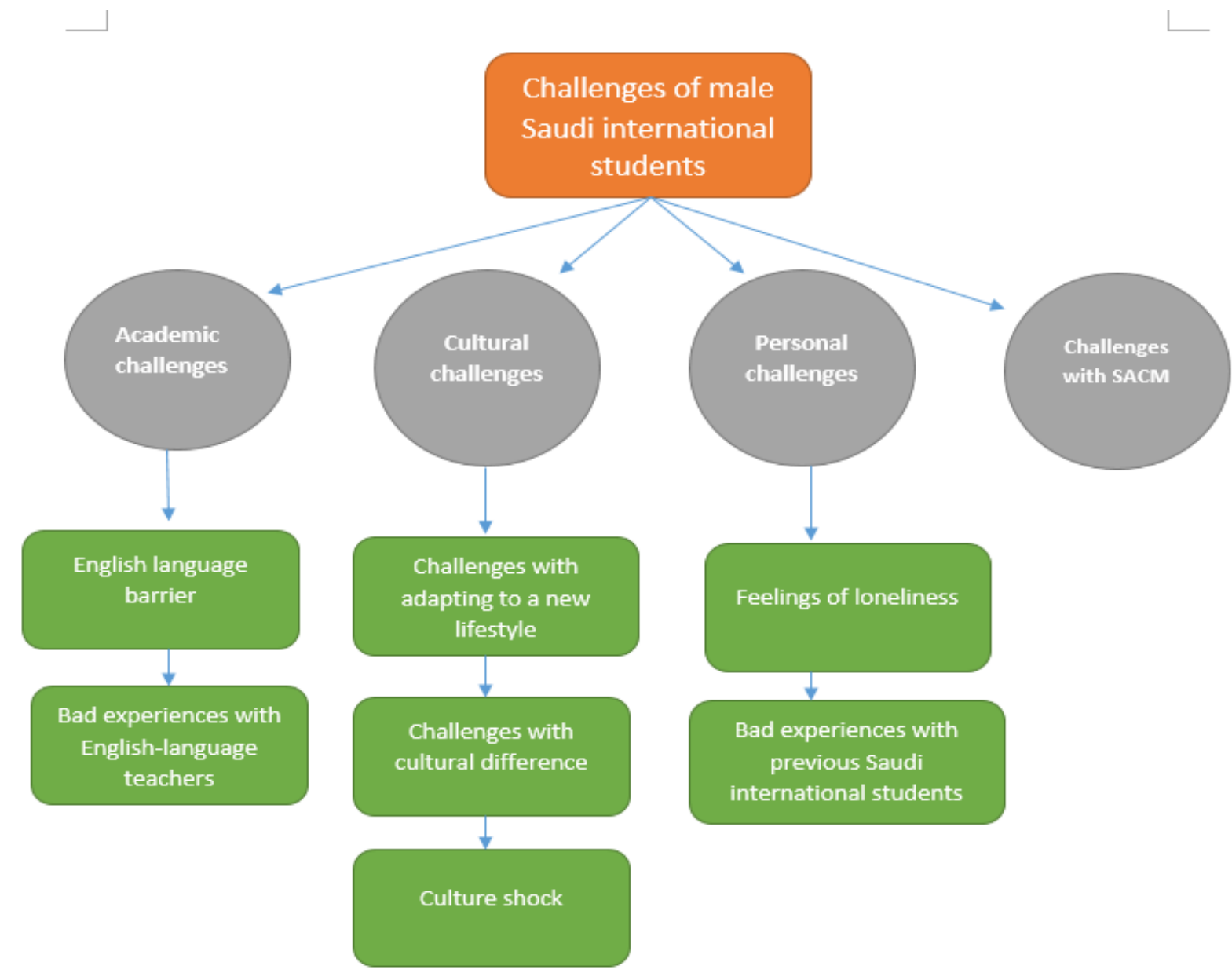

Chart 1: Challenges of male Saudi international students

\subsubsection{Academic challenges}

Participants stated that they experienced some academic challenges, including the English language barrier and bad experiences with English-language teachers.

\subsubsection{English language barrier}

As mentioned in section three of this paper, many researchers found that the English language is one of the obstacles facing international students (Al-Shehri 1989; Guantlett 2006; Hofer 2009; Jammaz 1972; Novera 2004; Sawir 2005; Shabeeb 1996; Sharma 1971), (See Sections 3.1.1.1). Participants in this study also stated that the English language is the big challenge:

Qasem: For me, the big challenge was the language barrier. I had only a basic knowledge of English, which I studied in intermediate and secondary stages as well as two English units in university, so it was big drawback. In fact, the language barrier was a big challenge everywhere in the first few weeks.

Fadi agrees with Qasem that the language barrier is one of the challenges that he experienced:

My English was also limited, but I could speak a little bit. The language barrier was one of the obstacles.

It seems like the reason for the language barrier is a weak command of English before coming to study in Australia, as Qasem indicated only a basic command of the language: I had only a basic knowledge of English, which I studied in intermediate and secondary stages as well as two English units in university, so it was big drawback.

Fadi said his English was limited when he came to study in Australia.

My English was also limited, but I can speak a little bit. However, the language barrier was one of my obstacles. These results support what Sawir (2005) found in his study on international students from five different countries: the source of their learning difficulties was based on the weakness of the students' language skills before coming to Australia (see Sections 3.1.1.1). 


\subsubsection{Bad experiences with English-language teachers}

An argument arose between the participants regarding acquiring English as a second language. While Thabit and Nader stated that the big responsibility is on learners, Hasan and Fadi argue that English-language teachers play a bigger role.

Thabit: English as a language is highly dependent on a person. The university provides all materials; everything to help you in your studying is available. Actually, it depends on you as a learner.

Nader supported Thabit by saying: I know acquiring a language is a complex process-the teacher is only one aspect - but the main responsibility is based on the students.

But Hasan narrated his bad experiences with English-language teachers: I agree with you, that learning a language depends on a person, if he worked hard or not, but sometimes, if you attend some institutions, you waste time. Particularly when you study with some teachers, that means you waste four hours every day. Frankly, some teachers had no good lesson plans, and they repeated the same lessons sometimes every two weeks. Sometimes, they said it is time for group discussion, and they did not monitor students and correct their mistakes. I do not want to make a general judgment about all teachers, but many teachers did this.

Fadi supported Hasan's opinions: Actually, I would argue here, according to teachers, they do play a big role. He is the facilitator; he guides you based on your level. He is the advisor. Maybe he will assist you, or maybe he might make you worse. Hasan said that, because of the weakness of some English-language teachers, he knows some students do not attend classes because they think it is a waste of time: I know some students, they sometimes did not attend class because they said it is a waste of time. So, I studied at home by myself; it was better than going to study with some teachers.

When I asked Hasan about the head of the institution, he spoke negatively: Me: Did you try to contact the director or head of the institution to complain? Hasan: At the beginning, I didn't have good enough English to enable me to express myself, but later on, when I wanted to transfer to study with a good teacher, they did not allow me to do that.

\subsubsection{Cultural challenges}

Participants experienced some cultural challenges, including adapting to a new lifestyle, cultural differences, and culture shock.

\subsubsection{Challenges with adapting to a new lifestyle}

There are many differences between the lifestyles of Saudi Arabia and Australia. Thabit describes them as totally different: Actually, everything here is different; the whole country is different. All systems are different from Saudi Arabia - like education, health, any system-totally different from Saudi Arabia. Thus, Saudi international students encountered some challenges regarding adapting to this new lifestyle. Fadi described one aspect of the Australian lifestyle, the closing of shops at 5 p.m., as a big challenge: One of the challenges is, you begin your study from 8 a.m. until 4 p.m. - and this is long hours for studying, and at the same time, you have to do many things, such as buying furniture. Actually, when I came back around 4:30, all shops closed at 5 p.m. Me: The lifestyle of Australia, including main shops closing at 5 p.m., was a challenge for you? Fadi: It was a big challenge for me.

Qasem mentioned another challenge regarding lifestyle, which is the procedure of looking for housing: The procedures of searching for a house are totally different from Saudi Arabia, like taking an appointment for inspection, filling out an application, paying a bond; it was very complicated.

\subsubsection{Challenges with cultural differences}

The literature review in section three showed that international students faced challenges in adjusting to a culture that differs from their own culture (Mukthyala 2013; Pan and Wong 2010). Saudi international students in Australia faced similar challenges. For instance, Jaber described that being single is challenging for him: The most difficult challenge facing me when I came here, to Australia, was that I was and still am single. And it is difficult as a single Muslim to live here.

Me: Could you please clarify this point? 
Jaber: Single, I mean girls here everywhere, and many things are open, not like Saudi Arabia. Here, you can try alcohol and drugs easily, but because it is prohibited in Islam, I don't and can't try it because I always remember that I am Muslim and I have to avoid these things.

He stated that he cannot form relationships with girls because it is prohibited in Islam, and he said that standards in Australia are more open regarding alcohol and drugs, unlike Saudi Arabia. Another point is the wearing of Hijab or abayah by Saudi women, which causes some challenges, according to Fadi: When my wife is with me in the shopping centre or on the train, people look at us like strangers. I read some questions in their eyes, like why wear things like this. I felt it was not good-looking, negative toward Hijab and abayah. Especially in summer, many people ask my wife, why do you wear abayah and Hijab? Isn't it hot? OK, who told you that it is because of the weather; it is religious beliefs.

Although Fadi felt he did not experience any type of discrimination in Australia explicitly, he felt it implicitly, when his wife was wearing Hijab. He said: I felt it was not good-looking, negative toward Hijab and abayah.

An additional point is food. Certain kinds of food are prohibited for Muslims. Therefore, Saudi international students are always looking for Halal food, which guarantees that as product does not contain any products prohibited by Islam law.

Nader described the issues regarding Halal food as nutritional shock: When I brought my family here, I faced a nutritional shock or food shock. My kids said, we want this, Daddy, please buy it. I said, OK, let me check if it is Halal or not. So always, they ask, is this thing Halal or not? Nader experienced this challenge because in Saudi Arabia, all food is Halal because it is an Islamic country, but in Australia, he always has to check if food is Halal or not. Consequently, some Saudi students buy food from Arabic shops, and some of them do not try to adapt to eat Australian food: Me: Did you try to adapt yourself to Australian food and avoid Arabic products? Fadi: In fact, I do not think that I tried, because the big issue regarding food is if it is Halal or not. When I buy from Arabic shops, I can guarantee that it is Halal. Also, I can't buy things that look strange to me.

\subsubsection{Culture shock}

Due to big differences between the cultures of Saudi Arabia and Australia, some participants experience culture shock: Thabit: For me, the problem was culture shock. When I was in Saudi Arabia, I heard about culture shock, then I read about culture shock and about Australia in general, so when I arrived here, the culture shock happened double to me. I read information on websites, umm, I can't say it was rubbish or right or wrong, but I found it different from the reality, that is, I mean, totally wrong according to my experience. Actually, everything here is different; a whole country is different. All systems are different from Saudi Arabia, like education, health, any system, totally different from Saudi Arabia.

Even when Thabit prepared himself before coming to study in Australia, he experienced double culture shock because the information that he read was different from the reality. It's not just international students who experience culture shock; so do their kids. Nader talked about his kids when they compared how their mother and Australian women dress: Nader: Regarding culture shock, my kids always ask me, why don't women wear Hijab or abayah, like Mum?

\subsubsection{Personal challenges}

Some challenges facing Saudi international students could be classified as personal, such as feelings of loneliness and bad experiences with previous Saudi international students.

\subsubsection{Feelings of loneliness}

It was found in section three that the majority of international students experience loneliness problems. Unlike the study of Sawiret al. (2008), which found that two-thirds (approximately 133 out of 200 students interviewed) have experienced loneliness problems, only one participant in this study has announced loneliness problems: Jaber: I experienced loneliness. When I came here, I lived for two days in my cousin's house, and then I moved to live in homestay, so I don't see my cousins many times except every weekend. The daily routine is boring. Every day, I am going to school and coming back in the afternoon, study a little bit, and then watch Arabic YouTube. If Jaber experienced loneliness problems, it might be because Jaber is the only single man among the participants and the others are married. 


\subsubsection{Bad experiences with previous Saudi international students}

To the best of the researcher's knowledge, this result was not discussed before, that previous Saudi international students convey their bad experiences to new Saudi international students, which causes depression and disappointment. Thabit narrated this bad experience as one of most challenging he faced: The biggest challenge was in the first two or three weeks, actually. In the English-language institution, I met some Saudi international students. They were very disappointed; they had bad experiences with the institution. They said: why did you come here, to this institution? It is not good, it is bad, they don't teach very well. That affected me so much, I remained depressed for two months, but at last, and I was convinced that English as a language is highly dependent on the person. The university provides all materials; everything to help you in your studying is available. It all depends on you as a learner.

Nader supported Thabit: I met many Saudi students with a pessimistic outlook. When I came to school the first thing after Asslamalikum, they said, why did you come here? Why did you choose to study at this university? It is too bad; it is not good and so on. Me: You mean your previous colleagues who currently study at the same institution? Nader: Yes, yes, my colleagues, so they disappointed me. Thabit and Nader agreed that, even though previous students had bad experiences, they shouldn't disappoint new students: Thabit: But even if we had bad experiences, we should not disappoint our colleagues.

\subsubsection{Challenges with the Saudi Cultural Mission (SACM)}

The Saudi Cultural Mission (SACM) is a government organisation located in Canberra that supervises all Saudi international students in Australia. In previous studies reviewed in Chapter II, Saudi international students did not announce problems with the SACM. However, some participants in this study announced some issues with the SACM. When Jaber first came in Australia, he needed to open a student file.

When I wanted to open a student's file at the Saudi Cultural Mission, it was not easy. You have to call them many times, and sometimes, no one responds to your calls. So I spent at least three months until they accepted my request and opened a student's file for me.

Fadi supported Jaber, and he said that staff did not respond to phone calls: When I called them, they did not respond, sometimes for more than a week. You called them, but no response. But when you asked through an electronic gate like a website, you received a reply without a reply, like please contact your supervisor. OK, but my supervisor did not respond or reply.

I asked what the reason from his perspective was: Me: Sorry, why do you think he did not reply? Was it because he supervised a huge number of students, or was he neglectful?

Fadi: No, I think even though he supervised a big number of students, he has pre-determined times for phone calls. So it is possible you call him for three to four days at different times, and you still get no response. Even if he has no time, what about e-mail?

Jaber commented about this situation: I think not all the staff of the Cultural Mission is like this, but there are many good employees who are helpful to students.

Although some researchers (see Sections 3.1.3.1) asserted that Saudi international students experience problems with finances (Hofer 2009; Sharma 1971) none of participants of this study announced that they experienced financial problems.

\section{Conclusion, Limitations \& Recommendations}

This study was aimed to answer this question: what are some challenges that male Saudis experience as international students in Australia? Participants mentioned some challenges that they have experienced as international students in Australia. These challenges are: firstly, academic challenges such as English language barrier and bad experience with English-language teachers. Secondly, cultural challenges such as challenges with adapting to a new lifestyle, challenges with cultural differences challenges with cultural differences and religion and culture shock. Thirdly, personal challenges such as feeling of loneliness and bad experiences with previous Saudi international students. Finally, challenges with the Saudi Cultural Mission (SACM). One of the limitations of this study is the small size of the participants (six male students). Therefore, the findings of this study are not generalizable. 
Bearing in mind that generalization of the findings is not one of the targets of this research, rather it is aimed at gaining deeper understanding about some challenges of male Saudi international students studying in Australia. Based on these results, the researcher suggest some recommendations for the Saudi government, who is sponsoring students;

Australian universities who host Saudi international students, and recommendations for future research. -Knowing that English language was the biggest obstacle for participants, the researcher suggest Saudi government to make intensive English courses for potential students who are going to study abroad before they travel overseas, to strengthen their language skills and avoid problems related to the language barrier.

For Australian universities, as participants announced challenges with some staff members in Australian universities, it would be better for Australian universities to prepare teachers of the English language how to deal with students from different cultures, especially from Saudi Arabia, which is completely different from Australia. This study was conducted on male only by using qualitative methodology; the researcher recommends future researches to be conducted with female Saudi international students to listen to their voices. Moreover, the researcher recommends the use of the mixed method, both qualitative and quantitative with larger samples of Saudi international students to enrich data.

\section{References}

Abualkhair, M. E. (2013). Arab Muslim International Students' Lived Experiences in a US Higher Education Institution. University of Missouri-Kansas City.

Alhazmi, A., \& Nyland, B. (2013). The Saudi Arabian international student experience: From a gender-segregated society to studying in a mixed-gender environment. Compare, 43(3), 346-365.

Al-Harthi, F. (1987). Saudi undergraduate students in U.S. universities: An exploratory study of their performance. Pittsburgh, PA, USA: University of Pittsburgh. ProQuest Dissertations and Theses.

Al-Jasir, A. (1993). Social, cultural, and academic factors associated with adjustment of Saudi students in the United States. Champaign-Urbana, IL, USA: University of Illinois at Champaign-Urbana. ProQuest Dissertations and Theses.

Al-Shehry, A. (1989). An investigation of the financial and academic problems perceived by Saudi graduate students while they are studying in the United States. (Order No. 9023701, Corvallis, OR, USA: Oregon State University). ProQuest Dissertations and Theses.

Alsulami, N. (2016), 'Cultural dimensions of conducting educational research: a case study of Saudi Arabia' in Baguley, Margaret (eds), Proceedings of Australian Association for Research in Education conference, Melbourne, 27 November -1 December 2016, The AARE website.

Ankawi, A. (2015), 'The academic writing challenges faced by Saudi students studying in New Zealand', Ph.D. thesis, Auckland: Auckland University of Technology.

Caldwell, J. D. (2013). Examining the experiences and adjustment challenges of Saudi Arabian students in the California state university system. (Order No. 3606395, California State University, Fresno, USA). ProQuest Dissertations and Theses, p. 261.

Binsahl, H. \&Shanton, C. (2012), 'International Saudi female students in Australia and social networking sites: what are the motivations and barriers to communication', 23rd ISANA International Education Association Conference Proceedings. ISANA International Education Association Inc., Auckland, New Zealand.

Binsahl, H., Shanton, C \&Bosua, R. (2015), 'Identity and belonging: Saudi female international students and their use of social networking sites', Crossings: Journal of Migration \& Culture, 6:1, pp.81-102.

Denzin, N. K., Miles, M. B., \& Huberman, M. (1995). Qualitative data analysis: An expanded sourcebook. Journal of Communication, 45(2), 177-184.

Hall, S. (1997), Cultural identity and diaspora. In Woodward, K. (Ed.), Identity and difference. London: Sage.

Hilal, K. (2013), 'Between the fears and hopes for a different future for the nation-states: Scholarship programs in Saudi Arabia and United Arab Emirates from a public policy standpoint', International Journal of Higher Education, 2:2, p.195-210

Hofer, V. J. (2009). The identification of issues serving as barriers to positive educational experiences for Saudi Arabian students studying in the state of Missouri. (Order No. 3392682, University of Missouri-Saint Louis, MO, USA). ProQuest Dissertations and Theses,, 270-n/a. 
Jammaz, A. I. A. (1972). Saudi students in the United States: A study of their adjustment problems. (Order No. 7305407, Michigan State University). ProQuest Dissertations and Theses, p. 143.

Khawaja, N. G. \&Demsey, J. (2008). A comparison of international and domestic tertiary students in Australia. Australian Journal of Guidance \& Counselling.18 (1), 30-46.

Midgely, W. (2009 a). They are, he is, and I am: Different adjustment accounts of two male Saudi Arabian nursing students at an Australian university. Studies in Learning, Evaluation, Innovation and Development, 6(1), 82-97.

Midgely, W. (2009 b). When we are at Uni our minds are at home: Saudi students worrying about wives. Paper presented at the ISANA international education association 20th international conference. From http://proceeding.com.au/isana2009/

Ministry of education (2017), King Salman Scholarship, https://departments.moe.gov.sa/Scholarship/RelatedDepartments/KingSalmanScholarship/Pages/default.a spx. Accessed 1December 2017.

Mukthyala, S. (2013). Lived Experiences of Indian International Students: Migration, Acculturation, and Resilience. ProQuest LLC. 789 East Eisenhower Parkway, PO Box 1346, Ann Arbor, MI 48106.

Novera, I. A. (2004). Indonesian postgraduate students studying in Australia: An examination of their academic, social and cultural experiences. International Education Journal, 5(4), 475-487.

Pan, J., M.D., \& Wong, D. F. K., M.D. (2011). Acculturative stressors and acculturative strategies as predictors of negative affect among Chinese international students in Australia and Hong Kong: A cross-cultural comparative study. Academic Psychiatry, 35(6), 376-81.

Rundles, K. (2013). Factors impacting the psychological adjustment of Saudi Arabian international students in the United States: Self-esteem, social support, and discrimination, Dissertation Abstracts International, B: Sciences and Engineering,

SACM (2015), Annual report of the Saudi cultural mission in Australia for 2015, https://www.sacm.org.au/books/flip/Report2015-2/FLASH/index.html, Accessed 1 December 2017.

Said, E. (1993), Culture and imperialism, New York: Vintage Books.

Shabeeb, S. S. (1996). Saudi and Arabian Gulf students' adjustment problems in Eastern Washington. (Order No. 9707506, Gonzaga University). ProQuest Dissertations and Theses, p. 162.

Sharma, S. (1971). A study to identify and analyse adjustment problems experienced by foreign non-European graduate students enrolled in selected universities in the state of North Carolina. (Order No. 7126942, The University of North Carolina at Greensboro). ProQuest Dissertations and Theses, p. 209.

Shaw, D. L. (2009) Bridging differences: Saudi Arabian students reflect on their educational experiences and share success strategies. (Order No. AAI3401195, Dissertation Abstracts International, The Humanities and Social Sciences, 1192.

Stewart. B. L. (2003) Culture shock: Rationale for including it in the FCS curriculum. Journal of Family and Consumer Sciences, 95, 105-108. 